\title{
Plant mortality on ultramafic soils after an extreme heat and drought event in the Mediterranean area
}

\author{
Andrea Coppi (D) Lorenzo Lazzaro (D) \\ Federico Selvi (10)
}

Received: 22 July 2021 / Accepted: 4 October 2021

(C) The Author(s), under exclusive licence to Springer Nature Switzerland AG 2021

\begin{abstract}
Aims Plant mortality associated with the growing frequency and intensity of heatwaves and dry spells is increasingly occurring in various ecosystems worldwide. However, the impacts of extreme events on plant communities of ultramafic soils are still unknown. Here, we describe a first case of plant mortality on serpentine outcrops in Italy following a heat and drought event that occurred between autumn 2016 and summer 2017.

Methods Mortality of perennial plants was assessed in thirty plots representing ten major serpentine areas
\end{abstract}

Responsible Editor: Susan Schwinning

Supplementary Information The online version contains supplementary material available at https://doi. org/10.1007/s11104-021-05179-2.

\section{A. Coppi}

Department of Biology, University of Firenze, Via P.A.

Micheli 1, I-50121 Florence, Italy

e-mail: andrea.coppi@unifi.it

\section{Lazzaro $(\bowtie)$}

Department of Biology, University of Firenze, Via G. La

Pira 4, I-50121 Florence, Italy

e-mail: lorenzo.lazzaro@unifi.it

\section{F. Selvi}

Department of Agriculture, Food, Environment and Forestry, Laboratories of Botany, University of Firenze, Piazzale delle Cascine 28, I-50144 Florence, Italy

e-mail: federico.selvi@unifi.it along a SW-NE gradient, with the sparse vegetation of ultramafic soils. Statistical modelling was based on temperature and precipitation data and local site conditions.

Results Responses of single species were largely different and not related to their taxonomic position, growth form or level of edaphic specialization for serpentine soils. Notably, obligate serpentine endemics were not less impacted than non-endemics. As expected, species mortality decreased with increasing chromosome number, suggesting higher tolerance and adaptive capacity in taxa of likely polyploid origin. Mortality increased with decreasing number of rainy days and duration of the heatwave and decreased with increasing distance from the Tyrrhenian coastline, reaching $60 \%$ in the southern and western areas with a Mediterranean climate. Local site conditions such as increasing soil depth and north-facing aspect significantly increased plant survivorship.

Conclusions Our findings show that extreme drought and heat can have a previously unrealized impact on ultramafic plant communities in the short term. Further studies should examine the recovery capacity and resilience of serpentine plants, together with the long term effects.

Keywords Climate change $\cdot$ Drought stress $\cdot$ Heat stress $\cdot$ Precipitation $\cdot$ Serpentine plants $\cdot$ Temperature 


\section{Introduction}

Since the few last decades, the frequency, intensity and duration of heatwaves and drought spells are increasing at the global scale (Perkins et al. 2012; IPCC 2019) and in the Mediterranean Basin, where the number of compound warm spells and droughts increased significantly over the last 40 years (Vogel et al. 2021). Climate change models have predicted a further increase of these events in the second half of the 21 century (Meehl and Tebaldi 2004, NAS 2016, IPPC 2019). The latest projections foresee increases in: mean temperature in most lands and oceans, hot extremes in most inhabited areas, heavy precipitation in several regions, and the probability of drought and precipitation deficits in some others (IPPC, 2018).

As a consequence, plant mortality has been shown to increase in many parts of the world. Recent studies have documented severe impacts on tree species survival in different continents and biome types, raising growing concern because of their potential to disrupt forest function worldwide (Gitlin et al. 2006; Allen et al. 2010; Senf et al. 2018; Crouchet et al. 2019). Furthermore, serious threats have been predicted concerning plant diversity (Thuiller et al. 2005) and endemic floras (Loarie et al. 2008). According to McDowell et al. (2008) climate warming and increased frequency of extreme events will probably cause increased regional mortality episodes, and multidecadal climate oscillations may increase plant susceptibility to drought-induced mortality by stimulating shifts in hydraulic architecture. More recently, Vogel et al. (2021) predicted that the increase in deseasonalised compound events (at their highest in spring and early summer) can potentially have a significant impact on the functioning of Mediterranean ecosystems as this is the peak phase of ecosystem productivity and a vital phenophase.

So far, however, drought and heat-induced mortality of plants other than trees in non-forest ecosystems remains undescribed. In particular, no data exist for pioneer plant communities that are formed by edaphic specialists and it is still poorly known how soil types with different physical and chemical characteristics can modulate the effects of heatwaves and drought on plants that grow on them. Ultramafic rocks across the world support paradigmatic examples of pioneer communities formed by edaphic specialists able to tolerate the selective pressure of the chemical and physical anomalies of the soils that originate from these rocks (serpentine soils; Kruckeberg 2002). These anomalies include the low $\mathrm{Ca}: \mathrm{Mg}$ ratio (usually $<1.0$ ), the $\mathrm{pH}$ values from basic to ultrabasic, the nutrient deficiency, especially in nitrogen and phosphorus, and the phytotoxic concentrations of metals (Brooks 1987). Tolerance to metals is a typical trait of the plants growing on these soils, which are in fact known as metallophytes (Wójcik et al. 2017). Moreover, the considerable amount of bare ground and the typical dark colour of serpentine soils caused by the high iron content produce unusual extremes of temperature, due to radiant losses and gains during the diurnal cycle (Brooks 1987; Cacho and Strauss 2014). Dark soils adsorb more solar radiation and pose more threats to plants than light soils because high soil temperatures may cause root injury (Hall 2001). Krause (1958) highlighted the strong microclimatic effect exerted by exposed serpentine soils on root systems due to their porous nature which permits elevated aeration. Moreover, Malpas (1992) pointed that their granular texture and shallowness results in a strong drainage and moisture deficiency even in regions with elevated rainfall. Another physical problem of serpentine soils is that the $\mathrm{Mg}$ excess causes the formation of stable viscous lumps which gives a stickiness to the soil material under wet conditions but dry out to a hard impermeable structure during drought (Brooks 1987). Such natural anomalies can be expected to be amplified during periods of high temperatures and intense drought, making serpentine soils a very hostile habitat but also a suitable system to study the impact of climate extremes on open plant communities formed by herbaceous and small-sized woody species. Although adaptation to water deficit and high temperatures are typical of serpentine plants thanks to their specific traits (Cacho and Strauss 2014; Rajakaruna 2017), their resistance cannot be unlimited and one may wonder how they respond when the intensity of these stress factors increase to unusual levels during heat waves and drought crisis. Indeed, climate extremes could be an underestimated but incumbent threat to metallicolous plants of ultramafic soils, besides those that have already been documented at the global and regional level (Whiting et al. 2004; Selvi et al. 2017). 
So far, the responses of these special communities to various scenarios of climate change have been under investigation mainly in western North America (Harrison et al. 2009, 2015; Fernandez-Going and Harrison 2013, Damschen et al. 2015; Copeland et al. 2016). These studies provided fundamental conceptual frameworks, working hypotheses and scenarios, highlighting that serpentine plants, as well as other edaphic specialists, can hardly move or migrate outside their native range because of the natural fragmentation of the outcrops (see also Corlett and Tomlinson 2020). Populations are often confined to their current "edaphic islands" and can become early victims of climate change if not able to tolerate or adapt in situ to the new conditions (Damschen et al. 2015). Adaptation timescales, however, are much longer than those of recent recurrent heat and drought waves linked to climate change, to which most species cannot respond with sufficiently rapid phenotypical or physiological responses. Hence, edaphic specialists may be mostly helpless in the face of these sudden events, which can have unpredictable impacts on their survival when tolerance limits are exceeded. High temperatures can have direct damaging effects associated with hot tissue temperatures or indirect effects associated with the plant-water-deficits that can arise due to high transpiration rates (Hall 2001). Extreme temperatures can in this way cause the premature death of plants, and if this happens for a significant proportion of individuals, a reduction of population size and genetic variability is to be expected, with further detrimental consequences on the species adaptive potential in the face of global change (Boulding 2009).

In this work, we describe a first case of plant mortality observed in open serpentine vegetation after a heat and drought event that occurred in Italy in the years 2016-2017. Based on temperature and precipitation data from the European Space Agency and regional sources, this event was very long (November 2016-September 2017) and intense due to unusually high summer temperatures and strong reduction of precipitation and soil moisture, especially in lowland areas with the Mediterranean or sub-Mediterranean climate (Magno et al. 2018).

The documented effects on evergreen and deciduous woody species in regional forests and maquis on various soil types, including serpentine, were impressive, and included widespread defoliation, partial or total desiccation of crowns and dieback of tree branches (Pollastrini et al. 2019). Using a field-based observational approach, in autumn 2017 we determined species-level mortality in thirty representative plots across ten major ultramafic outcrops in Tuscany, one of the richest regions in serpentine flora in Italy (Selvi 2007). Data were then analyzed to: compare responses of the different species in relation to their taxonomic/phylogenetic position, plant growth form, degree of edaphic specialization and chromosome number (aim 1), assess the relationship between mortality and local climate data (aim 2) and evaluate the effect of local site conditions (aim 3).

\section{Materials and Methods}

The climatic event

The year 2017 was characterized by a strong decline in soil moisture in most of southern Europe and especially in Italy, as documented by the European Space Agency (https://phys.org/news/2017-09-italy-droughtspace.html). In our study area, soil water deficit started in autumn and winter 2016 and increased in the following spring and summer (Magno et al. 2018). Variation of maximum daily temperatures from June to August 2017 and monthly precipitation during 2017, compared with the median values of the period 1975-2016, are shown in Figs. S1 and S2 in supplementary materials. Data were retrieved from eight interpolated weather stations of the Agri4Cast $25 \times 25 \mathrm{~km}$ grid closest to our ultramafic areas (https://agri4cast.jrc.ec.europa. eu/DataPortal/Index.aspx). The Agri4Cast grid is well suited for this purpose as it offers long-term data, not available for local weather stations. An increase in temperatures and a dramatic drop of precipitation are evident in all localities, in some of which peaks over $40^{\circ} \mathrm{C}$ were registered for more consecutive days between the end of July and the beginning of August.

Study area, field data collection and mortality assessment

The investigation was conducted in Tuscany, a region of central-western Italy with extensive outcrops of ultramafic rocks (Lazzarotto 1993). These belong to 
the so-called "Ligurids" formation and share a very similar mineralogical composition consequent to their common origin (Vergnano Gambi 1992). Our sampling was designed to cover the largest part of the latitudinal, longitudinal and altitudinal gradient of these outcrops, from $43^{\circ} 02^{\prime}$ to $43^{\circ} 54^{\prime} \mathrm{N}$, from $10^{\circ} 25^{\prime}$ to $12^{\circ} 04^{\prime} \mathrm{E}$ and from 130 to $625 \mathrm{~m}$ above sea level. This resulted in ten major areas sampled (Table 1). During autumn 2017 (September to November), each area was surveyed by placing three random $5 \times 5 \mathrm{~m}$ plots in outcrops with the typical garrigue-like vegetation of the Tuscan serpentine soils (the Armerio-Alyssetum bertolonii association; Chiarucci et al. 1995), resulting in a total of 30 plots surveyed (Table 1); only in one area (Riparbella) we selected only two plots because of human disturbance, which was compensated by adding a plot in the close and highly natural area of Caselli (4 plots). Tree and shrub cover (> $1.3 \mathrm{~m}$ ) and local site conditions potentially influencing plant growth and survival were recorded in each plot, such as slope aspect and inclination, depth of the bedrock barrier in the soil (mean of five points in the plot), percentage of solid parent rock and dominant texture at the soil surface, according to three major categories (thin gravel, coarse gravel and debris, solid rock; Table 1). Next, all species were recorded and counting of living and dead individuals was carefully made for each one to assess mortality (Gitlin et al. 2006). Because of the late season, this survey could not include the annual species (therophytes), which usually dry out soon after the release of the seeds in late spring or early summer. However, annuals represent only a minor proportion of the serpentine vegetation of Tuscany, which is mainly formed by perennials (both woody and herbaceous; Chiarucci et al. 1995).

Dead individuals of herbaceous perennials (hemicryptophytes), dwarf shrubs with woody base (chamaephytes) and shrubs (phanerophytes) were identified by the yellowish, reddish-brown or grey color of the photosynthetic organs, their position mostly incurved downwards and collapsed to the ground, and their dry and often fragile tissues; in addition, most of these individuals did not oppose any resistance when eradicated from the ground, due to the death of the root system. Anatomical observations on the roots of three representative species, the grass Festuca robustifolia, the chamaephyte Odontarrhena bertolonii and the perennial herb Plantago subulata
L. were also made to shed light on the possible causes of death. Transverse sections were obtained with a microtome, colored with toluidine blue and Lugol staining, and observed at a Zeiss light microscope with a digital camera.

Estimation of climatic data at the sampling sites

Since climatic data at the sampling sites during summer 2017 could not be directly measured at the plot level, we used data collected in ten Regional reference weather stations close to the ten areas, available from the Regional Hydrological and Geological Service (hereafter referred to as SIR, https://www.sir.toscana.it/). The Agri4Cast data used above to describe the extreme event in 2016-2017 were not helpful to this scope, due to the insufficient resolution of the $25 \times 25 \mathrm{~km}$ grid. We used precipitation and temperature data from 1 June 2017 to 31 August 2017, which represents the timeframe in which the heat waves were registered and that caused the major stress to the vegetation in the study area. For precipitation, we considered for each site the total millimeters of rainfall (Tot. rainfall) and the number of rainy days (Rainy days). For temperatures, we calculated for each site the mean of maximum daily temperatures (Mean $\mathrm{T}_{\text {Max }}$ ) and the maximum length of heat waves (Max Heat Wave Length), defined as the maximum number of consecutive days in which the daily $\mathrm{T}_{\text {Max }}$ was above the monthly mean of the $\mathrm{T}_{\mathrm{Max}}$. Table 2 summarizes the climatic variables for the ten areas which were used in the statistical models below.

\section{Data analysis}

We first determined the rate of mortality for each species across the areas, as the percentage of dead individuals and ratio alive:dead individuals. Next, mortality was examined in relation to the major plant growth forms in our species dataset: 1) hemicryptophytic (perennial) herbs, 2) hemicryptophytic (perennial) graminoids (e.g. including species of families Poaceae and Cyperaceae), 3) dwarf shrubs (chamaephytes and nano-phanerophytes), and 4) shrubs (phanerophytes); data were retrieved from Pignatti (2005) and Selvi (2007). Moreover, we compared mortality in three major edaphic groups of species: 1) obligate serpentinophytes (growing only on serpentine soils or nearly so in our region), 2) basiphilous species growing on serpentine but also on calcareous 


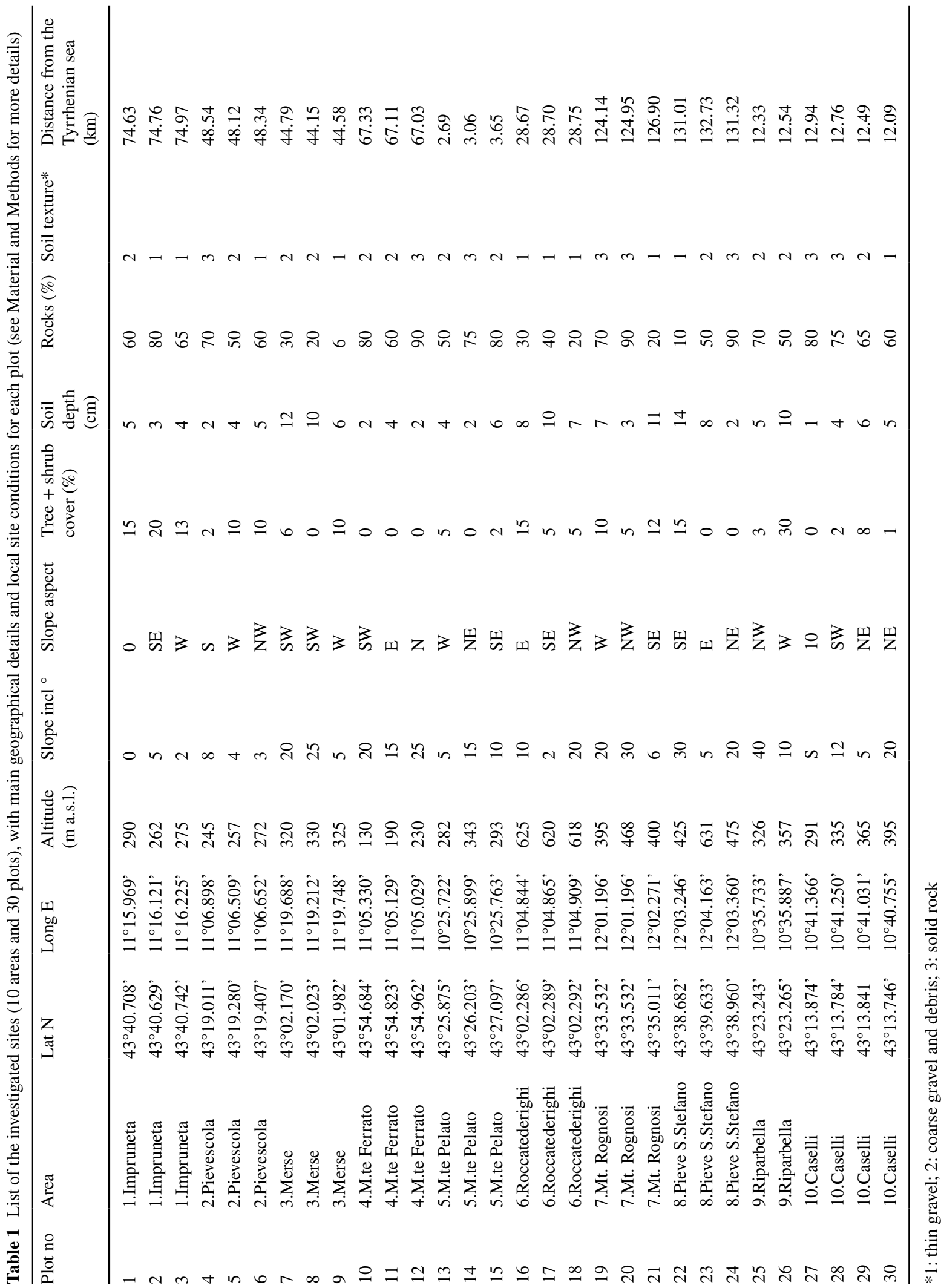


Table 2 Main climatic variables for the ten investigated areas in summer 2017, including an evaluation of heat waves, defined as periods of at least two consecutive days with maximum temperature above the monthly mean maximum temperature.

\begin{tabular}{|c|c|c|c|c|c|c|c|c|}
\hline Area & $\mathrm{T}_{\text {Mean }}\left({ }^{\circ} \mathrm{C}\right)$ & $\mathrm{T}_{\text {Max }}\left({ }^{\circ} \mathrm{C}\right)$ & $\begin{array}{l}\text { Number of } \\
\text { days above the } \\
\text { monthly Mean } \\
\mathrm{T}_{\text {Max }}\end{array}$ & $\begin{array}{l}\text { Number of } \\
\text { heat waves }\end{array}$ & $\begin{array}{l}\text { Mean heat wave } \\
\text { duration (num- } \\
\text { ber of days) }\end{array}$ & $\begin{array}{l}\text { Max heat wave } \\
\text { length (number } \\
\text { of days) }\end{array}$ & $\begin{array}{l}\text { Number of } \\
\text { rainy days }\end{array}$ & $\begin{array}{l}\text { Total } \\
\text { rainfall } \\
(\mathrm{mm})\end{array}$ \\
\hline 1.Impruneta & 33.0 & 41.4 & 51 & 9 & 5.6 & 12 & 6 & 62.8 \\
\hline 2.Pievescola & 33.2 & 42.2 & 55 & 7 & 6.4 & 13 & 9 & 47.6 \\
\hline 3.Merse & 33.2 & 41.6 & 53 & 8 & 5.3 & 12 & 7 & 53.2 \\
\hline 4.Mt. Ferrato & 32.9 & 40.8 & 53 & 9 & 5.7 & 12 & 7 & 26.4 \\
\hline 5.Mt. Pelato & 30.1 & 37.2 & 47 & 8 & 5.3 & 12 & 6 & 47.0 \\
\hline $\begin{array}{l}\text { 6.Roccated- } \\
\text { erighi }\end{array}$ & 30.2 & 38.8 & 46 & 9 & 4.8 & 8 & 12 & 35.2 \\
\hline 7.Mt. Rognosi & 31.9 & 39.9 & 53 & 8 & 5.4 & 9 & 17 & 95.4 \\
\hline $\begin{array}{l}\text { 8.Pieve } \\
\text { S.Stefano }\end{array}$ & 30.9 & 39.1 & 49 & 7 & 5.3 & 9 & 15 & 61.6 \\
\hline 9.Riparbella & 29.8 & 36.6 & 48 & 8 & 5.4 & 14 & 5 & 38.4 \\
\hline 10.Caselli & 31.2 & 38.0 & 49 & 7 & 5.0 & 18 & 6 & 47.2 \\
\hline
\end{tabular}

soils, and 3) "indifferent" species, those found on a variety of soil types, including serpentine; data were taken from Selvi (2007). Statistical comparisons between growth forms and edaphic groups were performed with non-parametric Kruskal-Wallis analysis of variance followed by a pairwise Mann-Whitney U-test.

We also related mortality to the somatic chromosome number of the taxa, based on information in the Chromosome Counts Database (CCDB, version 1.46; http://ccdb.tau.ac.il/) and Chrobase (http://bot.biolo gia.unipi.it/chrobase/index_actap.php). We examined the relationship between the two variables by means of a general linear model of regression. Thus, we compared the rate of mortality among diploids and putative polyploids, e.g. taxa with a high chromosome number divisible by four or more (Appels et al. 1998), using a non-parametric Mann-Whitney U Test.

Next, we used Generalized Least Squares (GLS) models to evaluate the effects of temperature, precipitation and local site conditions. These models allow to include a variance component term which accounts for a source of correlation between observations. In our case, we used an autocorrelation matrix accounting for the spatial autocorrelation within and among localities, thus also accounting for the effect of the hierarchical structure of our sampling design (i.e. plots nested within sampling areas). We selected the most adequate structure for the autocorrelation matrix comparing different models fitted with Gaussian, Linear, Ratio, and Spherical structure of the autocorrelation (Pinheiro et al. 2019). Finally, we selected the structure which minimized the Akaike information criterion (AIC) values. Considering that the fixed effect terms remained the same, in both the comparison procedure and the estimation of variance components, models were fitted with restricted maximum likelihood (REML).

First, we analyzed the effect of the climate variables potentially affecting plant survival at the plot level, namely temperature and precipitation. We fitted two separate GLS models, a first one to test the role of precipitation using the total millimeters of rainfall (Tot. rainfall) and the number of rainy days (Rainy days) as explanatory variables. A second GLS model was fitted to test the role the mean of maximum daily temperatures (Mean $\mathrm{T}_{\text {Max }}$ ) and the maximum length of heat waves (Max Heat Wave Length). In both of these models, we included two main components describing the climate features of the reference period: one accounting for the direct mean value of the climatic factors (i.e. total millimeters of rainfall and mean $\mathrm{T}_{\text {Max) }}$ and one accounting for the duration of the exposure to drought and heat (i.e. number of rainy days and length of heatwaves).

Next, we evaluated the role of the local site conditions. To this purpose, we fitted a series of GLS models with mortality as response variable and 
distance of the plots from the Tyrrhenian coastline $(\mathrm{km})$, northness, slope aspect, total vegetation cover, mean soil depth and rockiness as explanatory variables. Again, we added the proper variance component term accounting for spatial autocorrelation and nested structure. To evaluate the importance of predictors, we used the framework of multi-model inference through the Information-Theoretic Approach (Burnham and Anderson 2002) to select a set of "best models". Model comparisons were performed adopting the corrected AIC (AICc). We selected all the models with a $\triangle \mathrm{AICc}$ (which represents the difference between each model and the most parsimonious one) with values $<6$, as recommended in Richards (2008). According to this procedure, the correlation coefficients of each predictor were averaged among the selected best-fitting models and the significance of the estimated coefficient was calculated with a $z$-Wald test. We estimated the relative importance $w_{r(j)}$ of each predictor $j$ as the sum of the AICc weights across all models in which the selected predictor appeared (Burnham and Anderson 2002). Predictors with higher $w_{r(j)}$ (i.e. closer to one) have a greater weight of evidence to explain the response variable with the given data (i.e. higher relative importance). As the models shared the same variance component, but different fixed effect terms, they were fitted with maximum likelihood (ML) for the comparison and the "best models" were re-fitted with restricted maximum likelihood (REML) for the estimation and average of coefficients.

All statistical analyses were run in $\mathrm{R}$ vers. 4.0.0 ( $\mathrm{R}$ Core Team 2019), and relative graphs were produced with ggplot2 vers. 2.2.1 (Wickham 2009). The GLS models were fitted using the nlme package vers. 3.1143 (Pinheiro et al. 2019). The multi-model comparisons and inference was performed using the MuMIn package vers. 1.43.15 (Barton 2019).

\section{Results}

Mortality by species, functional group, chromosome number and edaphic category

Occurrence of plant species across the areas and plots, with number of estimated dead and living individuals and mean percentage of mortality per area is given in Supplementary Table S1. Total species mortality across all areas was $31.55 \%$ and the ratio alive:dead individuals was 2.17. Figure 1 shows examples of dead plants of regionally common serpentine species, three of which endemic (Odontarrhena bertolonii (Desv.) Jord \& Fourr., Armeria denticulata Bertol., Festuca robustifolia Markgr.-Dann.). Field and laboratory examination of dead plants of these and other species showed no signs of parasite attacks, damages by phytophagous insects or diseases by pathogenic fungi. In $O$. bertolonii (Fig. 2A,B) and $P$. subulata (Fig. 3C), the secondary phloem and xylem appeared not in contact to the vascular cambium, and the woody growth rings appeared incoherent in several points; in the latter species the cambium was dead and the primary cortex was disrupted. In $F$. robustifolia there were no apparent signs of tissue degeneration (Fig. 2D). Rate of mortality was largely variable between the 41 taxa in our dataset, ranging from 0 to $57 \%$ in Cistus creticus L. (Fig. 3); overall, the three species of Cistus were severely impacted (on average $47.9 \%$ of dead plants). In 14 taxa, mortality was over $20 \%$ and in 22 it was over $10 \%$, while no dead individuals were observed for 13 species. Mean rate of mortality of regional endemic species was $32 \%$, reaching $37 \%$ in the Ni-hyperaccumulator $O$. bertolonii (Fig. 1B,C,D; Fig. 3). At the family level, Plantaginaceae was the most affected group, followed by Rubiaceae and Poaceae. In grasses and most other families where average mortality was between 5 and $10 \%$, however, there were large differences between species of different genera, showing no relation between mortality and familial position. The four families in which no mortality was recorded consisted of succulent (Crassulaceae) or woody taxa (Oleaceae, Santalaceae, Anacardiaceae).

Small woody plants (dwarf shrubs: chamaephytes + nano-phanerophytes) suffered the highest mortality, followed by hemicryptophytic herbs and graminoids; larger woody taxa (shrubs: cespitose phanerophytes) were less affected (Fig. 3). However, large variation within all four functional types resulted in no statistical differences between them ( $p$-value $>0.05$ ). Mortality was higher in obligate serpentinophytes (median $21.7 \%$, mean $24.1 \%$ ) than in serpentine-calcicolous (median $13.5 \%$, mean $14.8 \%$ ) and edaphically indifferent species (median 1.3\%, mean 16.3\%), though differences were not significant ( $p$-value $>0.05$ ) due to large variation within the two latter groups. 

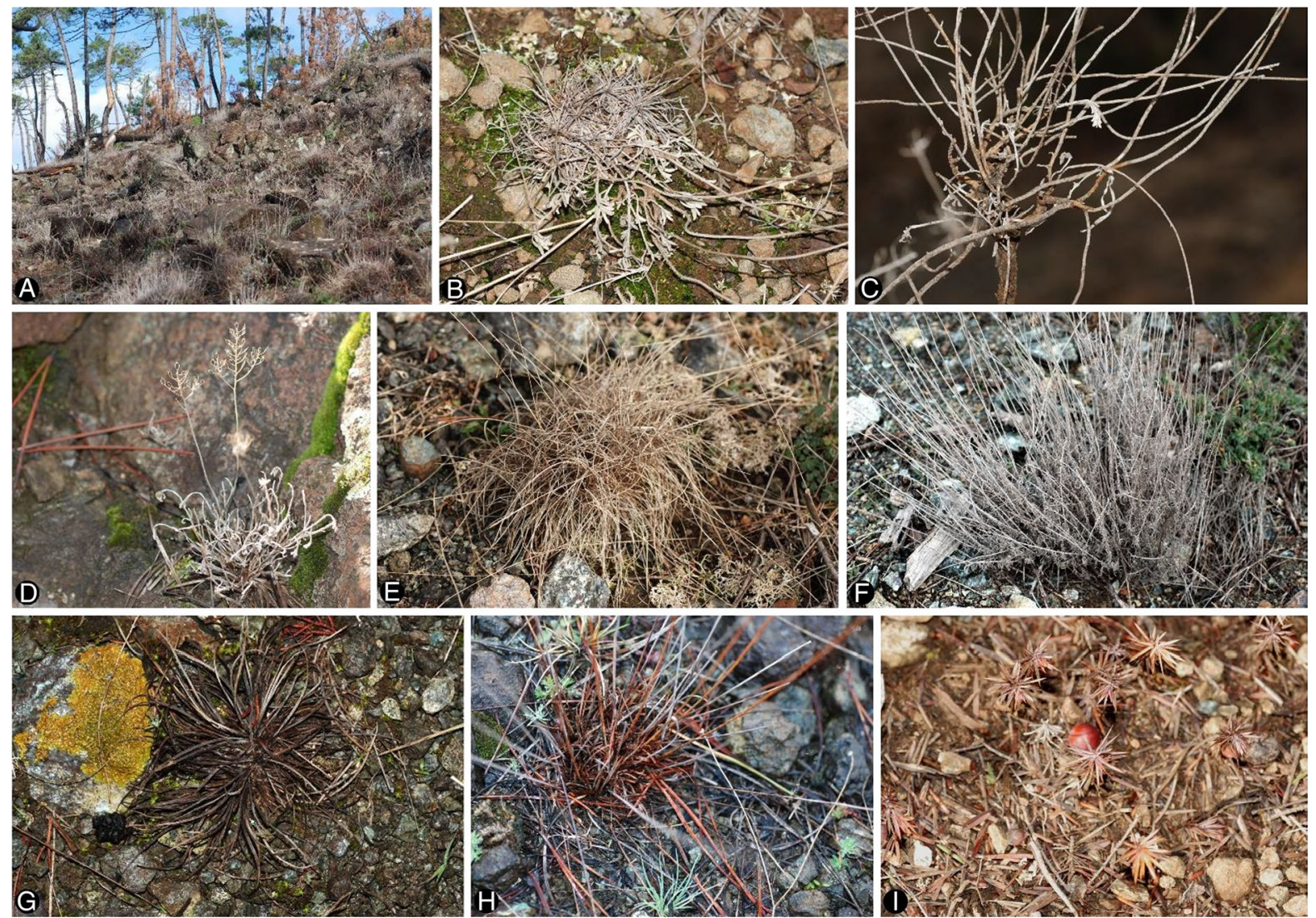

Fig. 1 Examples of serpentine landscapes and dead plants on Tuscan ultramafic outcrops in September-October 2017. A) Landscape at Mt. Ferrato (Prato province); B) Odontarrhena bertolonii, Merse; C) O. bertolonii, Caselli; D) O. bertolo-

Chromosome number was instead positively related to plant survivorship, as taxa with higher number had lower mortality ( $p$-value $=0.010$; Fig. $4 \mathrm{~A}$ ). Diploid species had a lower percentage of survivorship than putative polyploids (Mann Whitney $p$-value $=0.008$; Fig. 4B).

Mortality by plot and effect of climate and site conditions

The total amount of precipitation was not related to the mean rate of individual mortality across plots. However, the mean mortality of individuals was significantly affected by the number of rainy days during summer $(p$-value $=0.021$, Table 3 ); in particular, mortality decreased with the increase of the number of rainy days (Fig. 5A). Concerning the effect of nii, Mt Ferrato; E) Festuca robustifolia, Impruneta; F) Helichrysum italicum, Merse; G) Plantago subulata, Mt. Pelato; H) Armeria denticulata, Roccatederighi; I) Juniperus oxycedrus seedlings, Caselli

temperature, mortality was not affected by the mean $\mathrm{T}_{\text {Max }}$; however, there was a significant effect of the length of heat waves ( $p$-value $=0.039$, Table 2 ). Indeed, mortality increased with increasing maximum length of the heat waves (Fig. 5B).

Among site conditions, distance from the Tyrrhenian coastline was selected as important factor in most of the best-fitting models and had a significant effect on mortality, which decreased with distance from the sea (relative variable importance: $0.96, p$-value $=0.026$, Table 3, Fig. 6A). Total plant mortality by area ranged from over $12 \%$ in the eastern subcontinental area of Mt. Rognosi (Upper Tiber valley) to $60 \%$ in the western and southern areas of Monte Pelato, Caselli and Merse, with a typical Mediterranean climate. Other local site conditions selected as important factors in a high number of the 
Fig. 2 LM micrographs of cross-sectioned roots of dead plants of: A, B) Odontarrhena bertolonii, Root. 1 growth rings of secondary xylem; 2 line of vascular cambium; 3 secondary phloem; 4 cortex; 5 corky periderm; red arrows indicate the detachment between annual rings of secondary xylem; C) Plantago subulata, Root. 1 secondary xylem; 2 secondary phloem; 3 collapsed primary cortex; 4 periderm; red arrows indicate the line of detachment between growth rings (4-5) and that of dead vascular cambium; D) Festuca robustifolia. Root. 1 vascular cylinder with primary xylem and phloem; 2 endodermis; 3 cortex; 4 corky exodermis
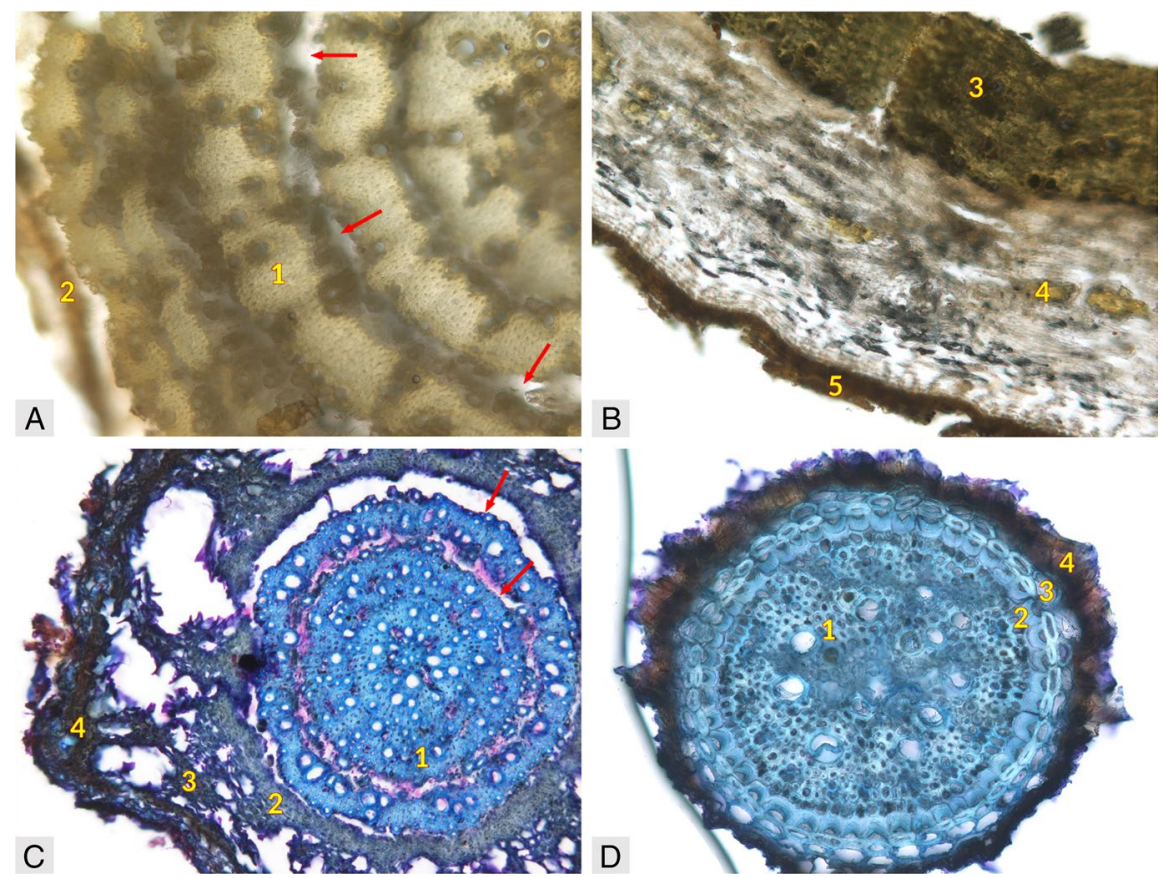

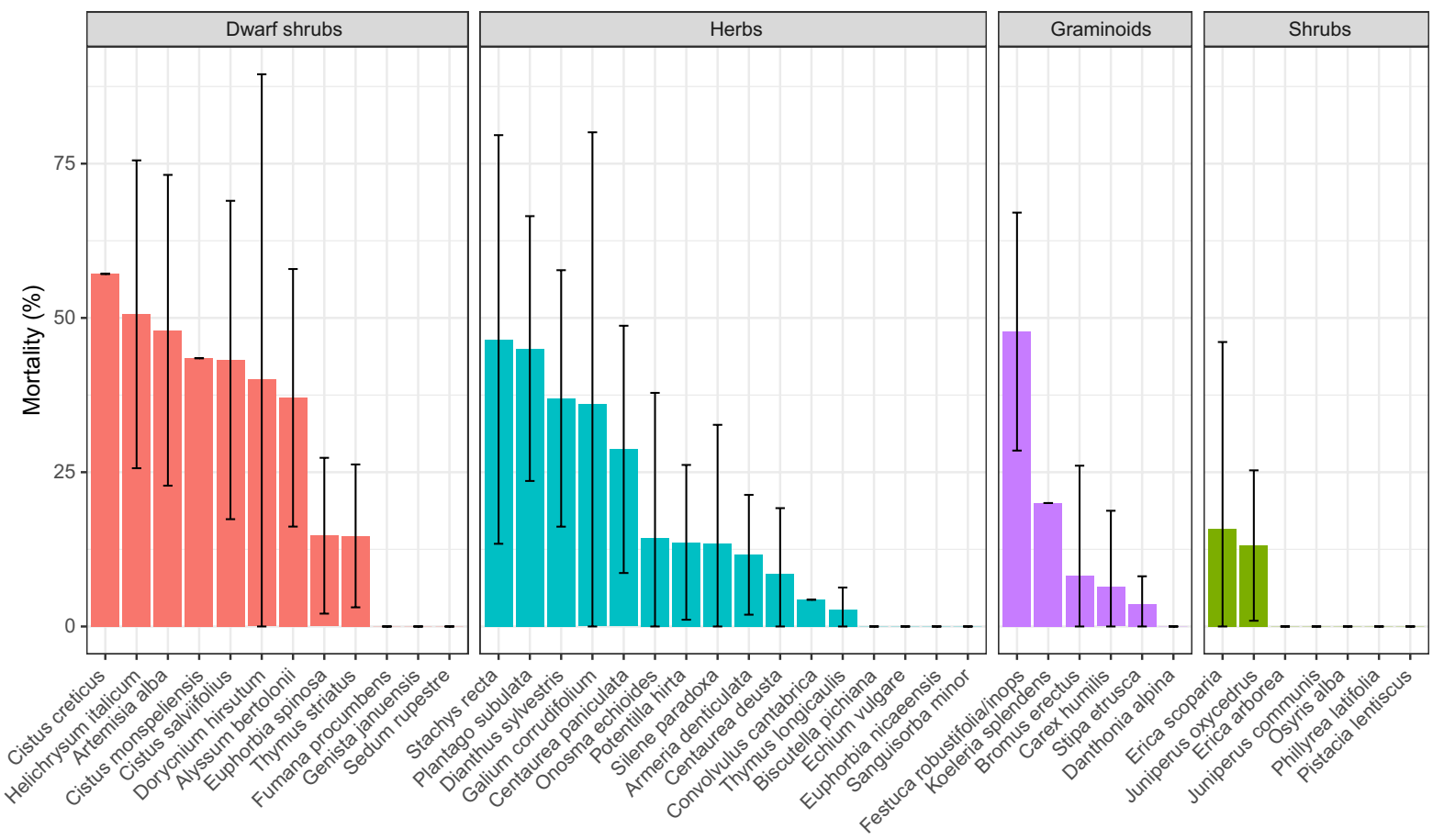

Fig. 3 Overall percentage of mortality by species and main growth forms, determined as the proportion of dead plants respective to the total number of counted individuals; error bars are standard deviations of species mortality across the plots where the species was recorded 

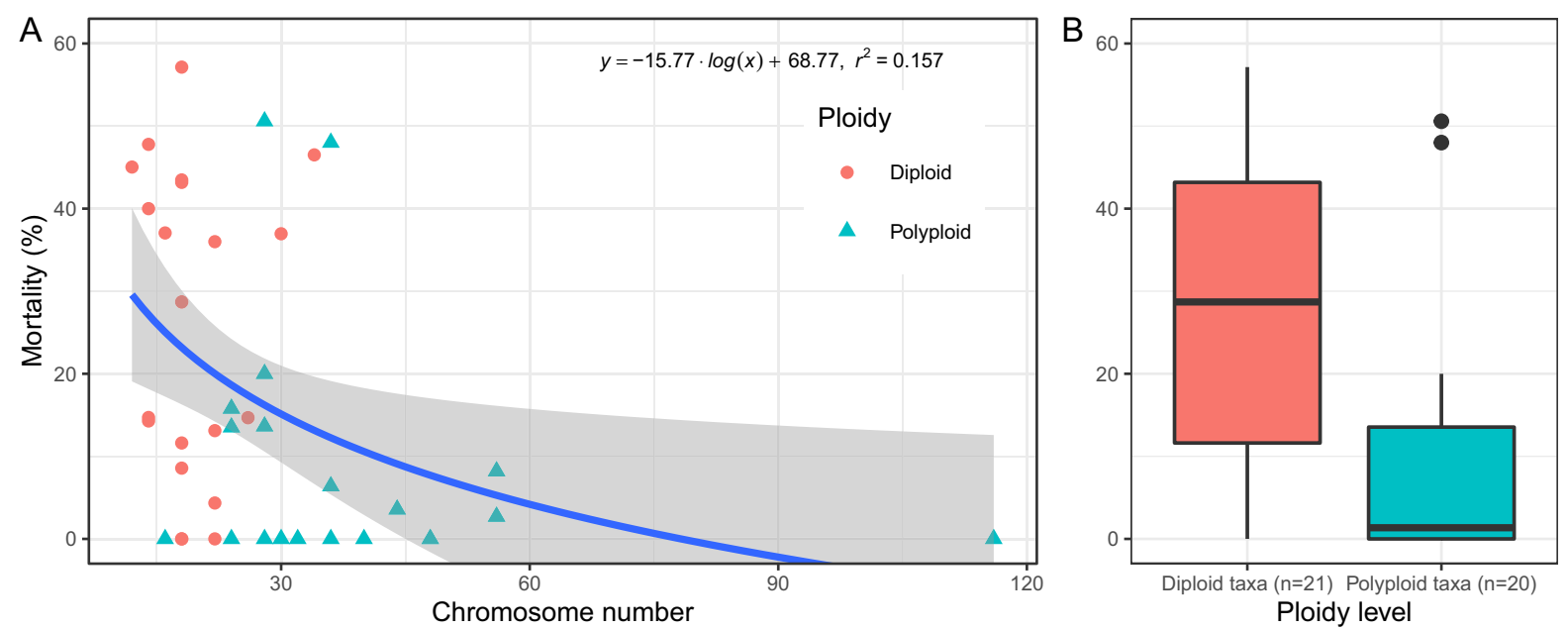

Fig. 4 A) Relationships between mortality and chromosome number of the species in the plots; B) Boxplot showing difference between diploid taxa and species of putative polyploidy origin

best-fitting models were the mean soil depth (relative variable importance: $0.90, p$-value $=0.009$, Table 4 ) and Northness (relative variable importance: 0.73, $p$-value $=0.004$, Table 4). Mortality decreased with increasing mean soil depth (Fig. 6B) and was lower in plots located on north-facing slopes (Fig. 6C).

\section{Discussion}

Serpentine plant specialists are considered well adapted to low moisture conditions and more able than nonserpentine plants to withstand increased aridity and high temperatures consequent to climate change (Rajakaruna 2017). Previous evidence also supports that plant communities on such infertile soils may be less sensitive to global warming thanks to their

Table 3 Results of Generalized Least Squares models on the role of rainfall and of maximum daily temperature of extremely hot days $\left(\mathrm{T}_{\mathrm{Max}}\right)$ on the mortality in the 30 monitored plots. Denominator degrees of freedom $=27$. Num DF $=$ Numerator stress-tolerant traits (Damschen et al. 2012; FernandezGoing et al. 2012; Harrison et al. 2015). Indeed, concerning Tuscan serpentines already Chiarucci et al. (1995) suggested that drought stress events may play a pivotal role in determining the typical scattered vegetation of these habitats, by causing recurrent episodes of local extinction of many late-successional species and favouring serpentine plant specialists (see also Chiarucci 2003). However, how these communities respond to the anomalous heat and drought that can occur on these soils during extreme events is still poorly known due to the scarcity of either observational or experimental studies. Recently Sianta and Kay (2019) suggested that obligate serpentine species (i.e. Californian serpentine endemics) should respond better than serpentine generalists to heat and drought events, being more adapted to bare habitats. In their study

degrees of freedom. Significance codes: $P$-value $<.001$ '***';

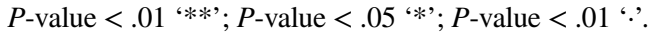

\begin{tabular}{llllll}
\hline Model & Term & Num DF & F-value & p value & \\
\hline Rainfall & (Intercept) & 1 & 94.36 & $<0.001$ & $* * *$ \\
& Tot. rainfall & 1 & 1.81 & 0.189 & $*$ \\
\multirow{3}{*}{ Temperature } & Rainy days & 1 & 6.01 & 0.021 & $* * *$ \\
& (Intercept) & 1 & 76.10 & $<0.001$ & $*$ \\
& Mean T & 1 & 0.03 & 0.873 & 0.039 \\
\hline
\end{tabular}


Fig. 5 A) Effect of number of rainy days on plant mortality by plot; B) Effect of heat waves length (number of days) on plant mortality by plot
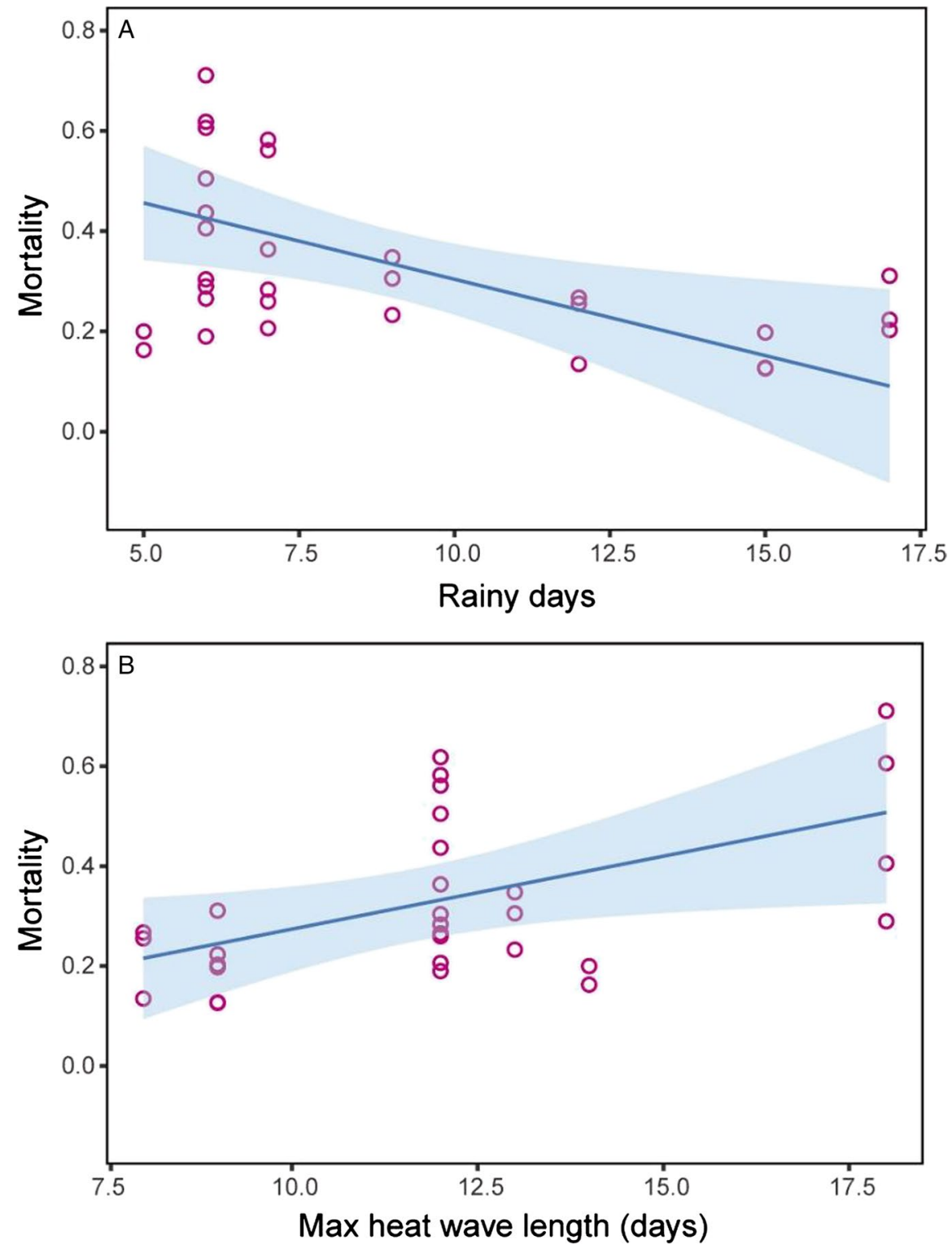

of the effects of drought on Californian herbaceous vegetation, Copeland et al. (2016) found a consistent decrease of cover and species richness in both serpentine and non-serpentine communities and little evidence for higher resistance to drought on serpentine soils, possibly due to severe conditions which may have exceeded tolerance thresholds for even the relatively stress-tolerant serpentine species. Our investigation goes in this direction and provides first circumstantial evidence of even more dramatic impacts that can occur when thresholds are exceeded to likely extreme levels. Both the anatomical observations of the root system of selected species and the largely synchronous death of individuals of taxonomically and functionally distant species supported that these were killed by a transversal abiotic factor, such as heat and drought.

Serpentine plant mortality across the study sites was widely variable across the 41 taxa found in the plots and largely species-specific. Moreover, it was not clearly associated with phylogenetic or taxonomic patterns, though some genera and families such as Cistaceae were significantly more affected than others. Growth form was also not relevant, though the taxa that suffered the highest mortality were 
Fig. 6 Effect on plant mortality of A) distance from the sea, B) mean soil depth, C) northness
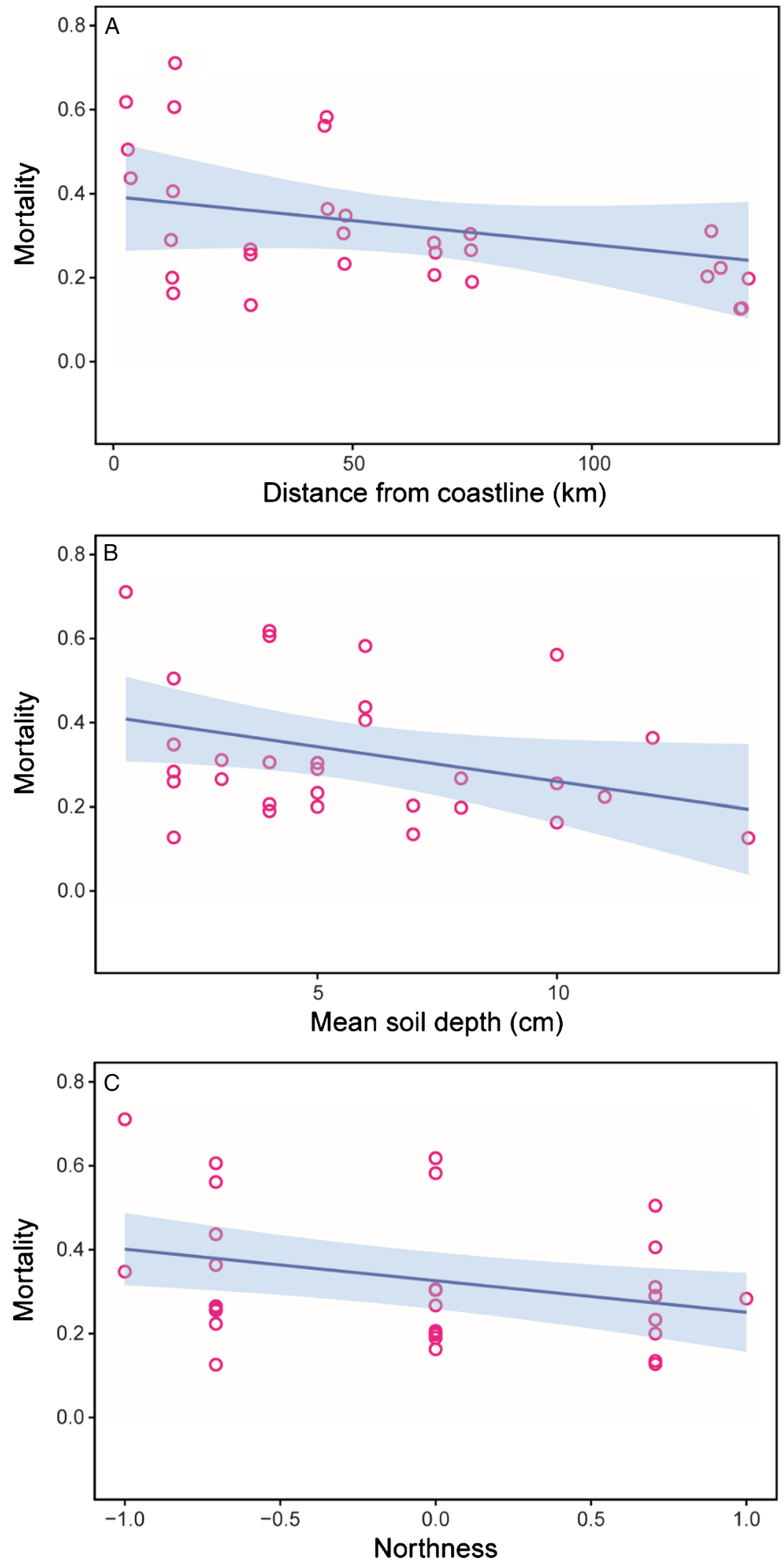
Table 4 Average coefficient and relative importance for each environmental predictor within the best Generalized Least Square models (AICc < 6) explaining the mortality in the 30 monitored plots. Significance codes: $P$-value $<.001^{\text {'***' }} ; P$-value $<.01$ ‘**'; $P$-value $<.05$ '*'.

\begin{tabular}{lllllll}
\hline Term & $\begin{array}{l}\text { Relative } \\
\text { importance }\end{array}$ & $\begin{array}{l}\text { Full Averaged } \\
\text { Coefficient }\end{array}$ & Adjusted SE & $z$ value & p Value & \\
\hline Intercept) & --- & 0.330 & 0.034 & 5.612 & $<0.001$ & $* * *$ \\
Distance from coastline & 0.96 & -0.068 & 0.029 & 2.225 & 0.026 & $*$ \\
Mean soil depth & 0.90 & -0.062 & 0.023 & 2.596 & 0.009 & $* *$ \\
Northness & 0.73 & -0.049 & 0.016 & 2.884 & 0.004 & $* *$ \\
Rockiness & 0.25 & -0.026 & 0.023 & 1.086 & 0.278 & \\
Slope & 0.22 & -0.017 & 0.017 & 0.985 & 0.325 & \\
Canopy cover & 0.08 & 0.006 & 0.015 & 0.378 & 0.705 & \\
\hline
\end{tabular}

prevalently small woody plants that are usually considered well adapted to summer-dry Mediterranean sites with strong solar radiation and shallow soils, such as Cistus creticus, Helichrysum italicum (Roth) G. Don and Artemisia alba Turra. Responses of the annual species could not be analysed here, though these plants are likely to suffer less than perennials, because of their rapid and short life-cycle that usually anticipates the summer drought and heat. Moreover, therophytes represent a very minor proportion of the garrigue-like serpentine vegetation in our region, ranging from $1-5 \%$ vs. $31-84 \%$ of hemicryptophytes and $16-57 \%$ of chamaephytes, based on the total number of species (Chiarucci et al. 1995). Unexpectedly, specialization for serpentine soils did not reduce the negative effect of drought and heat on the communities, as shown by the impact on the obligate endemics Odontarrhena bertolonii and Festuca robustifolia as well as on some preferential serpentinophytes such as Plantago subulata. The inconsistent relations between mortality, taxonomy, growth form and edaphism, suggest that resistance to extreme drought and/or temperature depends on structural and/or physiological species-specific traits, among which the water status management strategy may be a relevant one. According to McDowell et al. (2008), isohydric and anisohydric water potential regulation may partition species between survival and mortality. Anisohydric plants are often relatively drought tolerant but also at higher risk of hydraulic failure under severe stress than isohydric plants, because they keep their stomata open and photosynthetic rates high for longer periods, even in the presence of decreasing leaf water potential (Sade et al. 2012). In both cases, elevated temperatures can exacerbate hydraulic failure, and biotic agents may amplify and be amplified by drought-induced plant stress (McDowell et al. 2008).
The only variable considered in this study that was significantly associated with a reduction of mortality was increasing chromosome number. Most of the taxa with an elevated number of chromosomes in their somatic cells are of likely polyploid origin and have a relatively large genome size compared to related diploids (Appels et al. 1998). Polyploid plants usually show enhanced genomic plasticity and expression of fitness genes conveying higher vigor ("heterosis") and adaptive capacity to environmental disturbances and stresses (Stebbins 1950; Van de Peer et al. 2017), including drought (Maherali et al. 2009). For example, Hao et al. (2013) found that plants of Atriplex with higher ploidy level have consistently greater resistance to droughtinduced loss of hydraulic conductivity, while Rao et al. (2020) showed that tetraploids of Lycium possess a superior resistance under severe drought stress compared with diploids, thanks to a strongly increased production of abscissic acid. Similarly, Godfree et al. (2017) provided empirical evidence of fixed and homeostatic patterns of polyploid advantage in grasses exposed to drought and heat stress. Higher resistance and faster adaptability to habitat changes allowed by genome duplication are the main reasons why polyploids have been predicted to take advantage of the consequences of global change, and polyploidy have been even foreseen as a major speciation mechanism (Sessa 2019; Levin 2019). Hence, further studies on responses of serpentine plants or communities to climate change should also incorporate ploidy level of taxa and/or populations in models and conceptual frameworks predicting the likelihood of local extinction, in-situ adaptation or migration outside their native range (Harrison et al. 2009; Damschen et al. 2012; Corlett and Tomlinson 2020). 
Although the effects of water and temperature stress could not be separately assessed, the causal relationship between the event and the observed plant mortality on Italian serpentine outcrops is supported by the analysis of climatic variables and the local factors in modulating species responses. A first variable positively affecting plant survival was the number of rainy days during the summer months. Small precipitation events may be crucial for perennial serpentine species when distributed in more days, as they repeatedly reduce drought stress and lower the temperature at the air-soil interface through evaporation. On the contrary, when the number of rainy days during summer falls below a critical threshold, the prolonged lack of relief from internal water deficit exceeds tolerance limits of most species and cause severe stress. According to Onyekachi et al. (2019), events of prolonged drought associated with sudden shifts in precipitation regimes driven by climate changes often disturb plant metabolism and arrest photosynthesis, exposing non-adapted plants to premature death. When precipitation is abundant in a single event, as often during summer in the Mediterranean, serpentine outcrops are subject to a strong run-off and drainage because of the soil texture (Brooks 1987). Coupled with rapid evaporation caused by the high soil temperature, this is likely to prevent perennial plants with a deep root system to use water efficiently, ultimately accounting for the non-significant effect of the total amount of summer precipitation observed here.

Length of the heat waves was also significant in driving mortality of serpentine plants, while maximum daily temperatures in our study areas were apparently not relevant. Hence, the duration of the period with temperatures higher than usual had apparently a more severe impact than the intensity of single heat peaks. These findings are to be interpreted in the light of early studies showing that time of exposure to heat is crucial to cause plant death (Hare 1961) and that the relationship between time and temperature in perennial herbaceous species is an exponential function (Wright 1970). The lethal impact of these extreme temperatures can be supposed in the light of early evidence that that the so-called "thermal death point" (e.g. the lowest temperature that results in no survival after a fixed period of exposure) of numerous plants of temperate biomes lies between 50 and $55^{\circ} \mathrm{C}$ for the above-ground parts and ca. $45^{\circ} \mathrm{C}$ for the roots (Wright 1970). To test this hypothesis, more studies would be needed to investigate the thermal death points of serpentine plants, as well as their "thermal death time", e.g. the time of exposure at a given temperature required for death of the organism (Wright 1970). To date, however, very little is known about the effects of heat stress on serpentine plants, and this comes from a study on Alyssum species from Iran that showed decreased resistance with increasing $\mathrm{Ca}: \mathrm{Mg}$ ratio in the growing substrate (Ghasemi et al. 2015). Hence, further studies should investigate whether plant resistance to heat on ultramafic outcrops may be also affected by the element composition in the soil and the high levels of trace metals such as $\mathrm{Mg}, \mathrm{Ni}, \mathrm{Cr}$ and Co.

Local factors influencing microclimate such as slope aspect also modulated mortality. Serpentine communities on north-facing sites were on average less impacted than those on the south- or westfacing slopes due to the lower solar radiation, temperature and water stress, in line with evidence from other plant communities from dry regions of North America (Gitlin et al. 2006). Mortality at the plot scale was also reduced by the depth of the bedrock barrier in the soil, as this is a major factor increasing plant rooting depth and soil moisture retention at the global scale (Fan et al. 2017). Rooting depth is known to have a strong positive effect on survival in drought-adapted Mediterranean plants because associated with the ability to uptake water several centimeters below the soil surface (Padilla and Pugnaire 2007; Hidalgo-Triana and Pérez Latorre 2018; Bristiel et al. 2019). In our study we did not evaluated the contribution of litter cover on the ground, as in our sites litter is usually sparse and thin, thus unlikely to limit loss of water by evaporation. Also, mortality appeared negatively associated with the distance of the areas from the Tyrrhenian Sea, which, in our region, underlies the shift from the Mediterranean to the subcontinental climate. Baldi et al. (2006) evidenced that heat waves over Italy are generally a country-scale symptom of warm spells in the Mediterranean basin. Hence, it is conceivable that increasing distance from the Tyrrhenian sea may involve a reduction of heat spell magnitude or result in a decreasing temperature gradient. Distance from the sea also affects the precipitation regime by increasing the amount and frequency of rainfall during the summer months, potentially improving plant survivorship during 
extreme events. Nevertheless, the non-significant relation between mortality and $\mathrm{T}_{\text {Max }}$ discussed above would exclude a direct effect of the latter variable and further studies are needed to unravel the direct factors and mechanisms underlying this pattern.

In conclusion, the results of our study provide early circumstantial evidence that climate extremes, in the form of heat and drought events, are a previously unrealized threat to the persistence of species and populations of ultramafic plant communities, and ultimately, to the biodiversity of metallophytes. Further studies should also look at plant mortality in open vegetation of non-ultramafic soils and compare the responses of serpentine and non-serpentine populations of non-obligate serpentine species, to examine whether their response to extreme events is affected by soil type. Moreover, the impact of extreme drought and heat events on serpentine plants and communities may also appear during a prolonged recovery phase. According to McGillivray et al. (1995), resistance and resilience to drought may be even negatively linked in herbaceous plant communities, depending on species traits, competitive interactions, potential feedbacks and indirect effects through soil processes (see also Copeland et al. 2016). Hence, a deeper understanding of the impact of such events would require to monitor changes over a longer period through a system of permanent plots, as well as a better understanding of the various means and adaptive strategies that may allow recovery of serpentine plants in the long-term.

Acknowledgments Authors wish to acknowledge Isabella Bettarini for valuable help during field work, Filippo Bussotti and Martina Pollastrini for useful discussion on plant mortality associated with climate extremes. We would also like to thank Ilaria Colzi for critical reading our manuscript and providing valuable comments. We finally wish to thank three anonymous reviewers whose comments/suggestions helped to improve the first version of our manuscript.

Availability of data and material All data are provided as supplementary materials

Authors' Contributions FS conceived the ideas and designed the methodology and collected the data. LL and FS analysed and interpreted the data. AC, FS and LL led the writing of the manuscript and contributed critically to the drafts and gave final approval for publication.

Funding Research funds to FS from the Italian Ministry for University and Research and University of Firenze are acknowledged.

\section{Declarations}

Conflicts of interest/Competing interests (include appropriate disclosures) The authors declare no competing interests.

Code availability 'Not applicable'

\section{References}

Allen CD, Macalady AK, Chenchouni H, Bachelet D, McDowell N, Vennetier M, Kitzberger T, Rigling A, Breshears DD, Hogg EH, Gonzalez P, Fensham R (2010) A global overview of drought and heat-induced tree mortality reveals emerging climate change risks for forests. For Ecol Manag 259:660-684

Appels R, Morris R, Gill BS, May CE (1998) Chromosome Biology, pp. 67-84. Springer

Baldi M, Dalu G, Maracchi G, Pasqui M, Cesarone F (2006) Heat waves in the Mediterranean: a local feature or a larger-scale effect? Int. J. Climatol. 26(11):1477-1487

Barton K (2019) MuMIn: Multi-Model Inference. R package version 1(43): 15

Blasi C (2010) La vegetazione d'Italia. Palombi Ed, Roma

Boulding EG (2009) Genetic Diversity, Adaptive Potential, and Population Viability in Changing Environments. In: Carroll SP, Fox CW (Eds), Conservation Biology. Evolution in Action, $1^{\circ}$ Ed., chapter 13 . Oxford University Press pp 199

Bristiel P, Roumet C, Violle C, Volaire F (2019) Coping with drought: root trait variability within the perennial grass Dactylis glomerata captures a trade-off between dehydration avoidance and dehydration tolerance. Plant Soil 434: 327-342. doi: 10.1007

Brooks RR (1987) Serpentine and its Vegetation. Dioscorides Press, Portland, Oregon

Burnham KP, Anderson DR (2002) Model selection and multimodel inference: a practical information-theoretic approach. Second edition. Springer-Verlag, New York, pp 528

Cacho NI, Strauss SY (2014) Occupation of bare habitats, an evolutionary precursor to soil specialization in plants. Proc Nat Acad Sci USA 111:15132-15137

Chiarucci A (2003) Vegetation ecology and conservation on Tuscan ultramafic soils. Bot Rev 69(3):252-268

Chiarucci A, Foggi B, Selvi F (1995) Garrigue plant communities of ultramafic outcrops of Tuscany (Central Italy). Webbia 49:179-192

Chiarucci A, Robinson BH, Bonini I, Petit D, Brooks RR, De Dominicis V (1998) Vegetation of Tuscan ultramafic soils in relation to edaphic and physical factors. Folia Geobot 33(2):113-131

Copeland SM, Harrison SP, Latimer AM, Damschen EI, Eskelinen AM, Fernandez-Going B, Spasojevic MJ, Anacker BL, Thorne JH (2016) Ecological effects of extreme drought on Californian herbaceous plant communities. Ecol Monogr 86:295-311 
Corlett RT, Tomlinson KW (2020) Climate Change and Edaphic Specialists: Irresistible Force Meets Immovable Objects? Trends Ecol Evol 35:367-376

Crouchet SE, Jensen J, Schwartz BF, Schwinning S (2019) Tree mortality after a hot drought: distinguishing densitydependent and -independent drivers and why it matters. Front For Glob Change 2:1-21

Damschen EI, Harrison S, Ackerly DD, Fernandez-Going B, Anacker BL (2012) Endemic plant communities on special soils: early victims or hardy survivors of climate change? J Ecol 100:1112-1130

Fan Y, Miguez-Macho G, Jobbágy EG, Jackson RB, OteroCasal C (2017) Hydrologic regulation of plant rooting depth. Proc Nat Acad Sci USA 114:10572-10577

Fernandez-Going BM, Anacker BL, Harrison SP (2012) Temporal variability in California grasslands: soil type and species functional traits mediate response to precipitation. Ecology 93:2104-2114

Fernandez-Going BM, Harrison S (2013) Effects of experimental water addition depend on grassland community characteristics. Plant Ecol 214:777-786. https://doi.org/ 10.1007/s11258-013-0207-9

Ghasemi R, Chavoshi ZZ, Boyd RS, Rajakaruna ND (2015) Calcium:magnesium ratio affects environmental stress sensitivity in the serpentine-endemic Alyssum inflatum (Brassicaceae). Austral J Bot 63:39-46

Gitlin AR, Sthultz CM, Bowker MA, Stumpf PKL, Kennedy K, Munoz A, Bailey JK, Whitham TG (2006) Mortality gradients within and among dominant plant populations as barometers of ecosystem change during extreme drought. Conserv Biol 20:1477-1486

Godfree RC, Marshall DJ, Young AG, Miller CH, Mathews S (2017) Empirical evidence of fixed and homeostatic patterns of polyploid advantage in a keystone grass exposed to drought and heat stress. R Soc Open Sci 4:170934

Hall AE (2001) Crop Responses to Environment. CRC Press LLC, Boca Raton, Florida

Hao G-Y, Lucero ME, Sanderson SC, Zacharias EH, Holbrook NM (2013) Polyploidy enhances the occupation of heterogeneous environments through hydraulic related tradeoffs in Atriplex canescens (Chenopodiaceae). New Phytol 197:970-978

Hare RC (1961) Heat effects on living plants. US Dep Agr Occas Pap 183:1-32

Harrison SP, Damschen EI, Fernandez-Going B (2009) Climate Gradients, Climate Change, and Special Edaphic Floras. Northeastern Naturalist 16:121-130

Harrison SP, Damschen EI, Fernandez-Going B, Eskelinen AM, Copeland S (2015) Plant communities on infertile soils are less sensitive to climate change. Ann Bot 116:1017-1022

Hidalgo-Triana N, Pérez Latorre AV (2018) Thorne JH (2018) Plant functional traits and groups in a Californian serpentine chaparral. Ecol Res 33:525-535. https://doi.org/10. 1007/s11284-017-1532-6

IPCC (2018) Global Warming of $1.5^{\circ} \mathrm{C}$. An IPCC Special Report on the impacts of global warming of $1.5^{\circ} \mathrm{C}$ above pre-industrial levels and related global greenhouse gas emission pathways, in the context of strengthening the global response to the threat of climate change, sustainable development, and efforts to eradicate poverty
[Masson-Delmotte, V., P. Zhai, H.-O. Pörtner, D. Roberts, J. Skea, P.R. Shukla, A. Pirani, W. Moufouma-Okia, C. Péan, R. Pidcock, S. Connors, J.B.R. Matthews, Y. Chen, X. Zhou, M.I. Gomis, E. Lonnoy, T. Maycock, M. Tignor, and T. Waterfield (eds.)]. In Press. Available at https:// www.ipcc.ch/sr15/. Accessed 24 Sep 2021

IPCC (2019) Climate Change and Land: an IPCC special report on climate change, desertification, land degradation, sustainable land management, food security, and greenhouse gas fluxes in terrestrial ecosystems [P.R. Shukla, J. Skea, E. Calvo Buendia, V. Masson-Delmotte, H.-O. Pörtner, D. C. Roberts, P. Zhai, R. Slade, S. Connors, R. van Diemen, M. Ferrat, E. Haughey, S. Luz, S. Neogi, M. Pathak, J. Petzold, J. Portugal Pereira, P. Vyas, E. Huntley, K. Kissick, M. Belkacemi, J. Malley, (eds.)]. In press. Available at https://www.ipcc.ch/srccl/. Accessed 24 Sep 2021

Loarie SR, Carter BE, Hayhoe K, McMahon S, Moe R, Knight CA, Ackerly DD (2008) Climate Change and the Future of California's Endemic Flora. PLoS ONE 3(6):e2502. https://doi.org/10.1371/journal.pone.0002502

Krause W (1958) Andere Bodenspezialisten. In: Handbuch der Pflanzenphysiologie v. 4. Springer Berlin, 755-806

Kruckeberg AR (2002) Geology and Plant Life. University of Washington Press

Lazzarotto A (1993) Elementi di Geologia. In: Giusti F (ed) La storia naturale della Toscana meridionale. Pizzi, Siena, pp 19-87

Levin DA (2019) Plant speciation in the age of climate change. Ann Bot 124:769-775

Magno R, De Filippis T, Di Giuseppe E, Pasqui M, Rocchi L, Gozzini B (2018) Semi-Automatic operational service for drought monitoring and forecasting in the Tuscany region. Geosciences 8:49. https://doi.org/10.3390/geoscience s8020049

Maherali H, Walden AE, Husband BC (2009) Genome duplication and the evolution of physiological responses to water stress. New Phytol 184:721-731

Malpas J (1992) Serpentine and geology of serpentinised rocks. In: Roberts BA, Proctor J (eds) The ecology of areas with serpentinized rocks - a world view. Kluwer Academic Publishers, Dordrecht, pp 7-30

McDowell N, Pockman WT, Allen CD, Breshears DD, Cobb N, Kolb T, Plaut J, Sperry J, West A, Williams DG, Yepez EA (2008) Mechanisms of plant survival and mortality during drought: why do some plants survive while others succumb to drought? New Phytol 178:719-739

Meehl GA, Tebaldi C (2004) More intense, more frequent, and longer lasting heat waves in the 21 st century. Science 305:994-997

Onyekachi OG, Boniface OO, Gemlack NF, Nicholas N (2019) The effect of climate change on abiotic plant stress: A review. Abiotic and Biotic Stress in Plants. https://doi.org/ 10.5772/intechopen.82681

Padilla FM, Pugnaire FI (2007) Rooting depth and soil moisture control Mediterranean woody seedling survival during drought. Funct Ecol 21:489-495

Perkins SE, Alexander LV, Nairn JR (2012) Increasing frequency, intensity and duration of observed global heatwaves and warm spells. Geophys Res Lett 39:L20714

Pignatti S (2005) Valori di Bioindicazione delle piante vascolari della Flora d'Italia. Braun-Blanquetia 39:1-97 
Pinheiro J, Bates D, DebRoy S, Sarkar D (2019) nlme: Linear and Nonlinear Mixed Effects Models. R package version 3.1-143. https://CRAN.R-project.org/package=nlme. Accessed 18 Dec 2019

Pollastrini M, Puletti N, Selvi F, Iacopetti G, Bussotti F (2019) Widespread crown defoliation after a drought and heat wave in the forests of Tuscany (Central Italy) and their recovery-A case study from summer 2017. Front For Glob Change 2:1-8

R Core Team (2019) R: A language and environment for statistical computing. R Foundation for Statistical Computing, Vienna, Austria. URL https://www.R-project.org/. Accessed 18 Dec 2019

Rao S, Tian Y, Xia X, Li Y, Chen J (2020) Chromosome doubling mediates superior drought tolerance in Lycium ruthenicum via abscisic acid signaling. Hortic Res 7:40

Rajakaruna N (2017) Lessons on evolution from the study of edaphic specialization. Bot Rev 84:39-78

Richards SA (2008) Dealing with overdispersed count data in applied ecology. J Appl Ecol 45:218-227

Sade N, Gebremedhin A, Moshelion M (2012) Risk-taking plants: anisohydric behavior as a stress-resistance trait. Pl Signal Behav 7(7):767-770

Selvi F (2007) Diversity, geographic variation and conservation of the serpentine flora of Tuscany (Italy). Biodiv Cons 16:1423-1439

Selvi F, Carrari E, Colzi I, Coppi A, Gonnelli C (2017) Responses of serpentine plants to pine invasion: Vegetation diversity and nickel accumulation in species with contrasting adaptive strategies. Sci Tot Environ 595:72-80

Senf C, Pflugmacher D, Zhiqiang Y, Sebald J, Knorn J, Neumann M, Hostert P, Seidl R (2018) Canopy mortality has doubled in Europe's temperate forests over the last three decades. Nat Commun 9:4978. https://doi.org/10.1038/ s41467-018-07539-6

Sessa EB (2019) Polyploidy as a mechanism for surviving global change. New Phytol 221:5-6
Sianta SA, Kay KM (2019) Adaptation and divergence in edaphic specialists and generalists: serpentine soil endemics in the California flora occur in barer serpentine habitats with lower soil calcium levels than serpentine tolerators. Am J Bot 106(5):690-703

Van de Peer Y, Mizrachi E, Marchal K (2017) The evolutionary significance of polyploidy. Nat Rev Genet 18:411-424

Thuiller W, Lavorel S, Araújo MB, Sykes MT, Prentice IC (2005) Climate change threats to plant diversity in Europe. Proc Natl Acad Sci USA 102: 8245-8250.Vergnano Gambi O (1992) The distribution and ecology of the vegetation of ultramafic soils in Italy. In: Roberts BA, Proctor J (eds) The Ecology of Areas with Serpentinized Rocks-A World View. Kluwer Academic Publishers, Dordrecht, pp 217-247

Vogel J, Paton E, Aich V, Bronstert A (2021) Increasing compound warm spells and droughts in the Mediterranean Basin. Weather Clim. Extrem 32:100312

Whiting SN, Reeves RD, Richards D, Johnson MS, Cooke JA, Malaisse F, Paton A, Smith JAC, Angle JS, Chaney RL, Ginocchio R, Jaffré T, Johns R, McIntyre T, Purvis OW, Salt DE, Schat H, Zhao FJ, Baker AJM (2004) Research priorities for conservation of metallophyte biodiversity and their potential for restoration and site remediation. Restor Ecol 12:106-116

Wójcik M, Gonnelli C, Selvi F, Dresler S, Rostański A, Vangronsveld J (2017) Metallophytes of serpentine and calamine soils -their unique ecophysiology and potential for phytoremediation. Adv Bot Res 83:1-42

Wright HA (1970) A Method to Determine Heat-Caused Mortality in Bunchgrasses. Ecology 51:582-587

Publisher's note Springer Nature remains neutral with regard to jurisdictional claims in published maps and institutional affiliations. 